\title{
Destructive Testing of HFIR Irradiation Rabbit Capsules to Establish Containment Safety Limitations
}
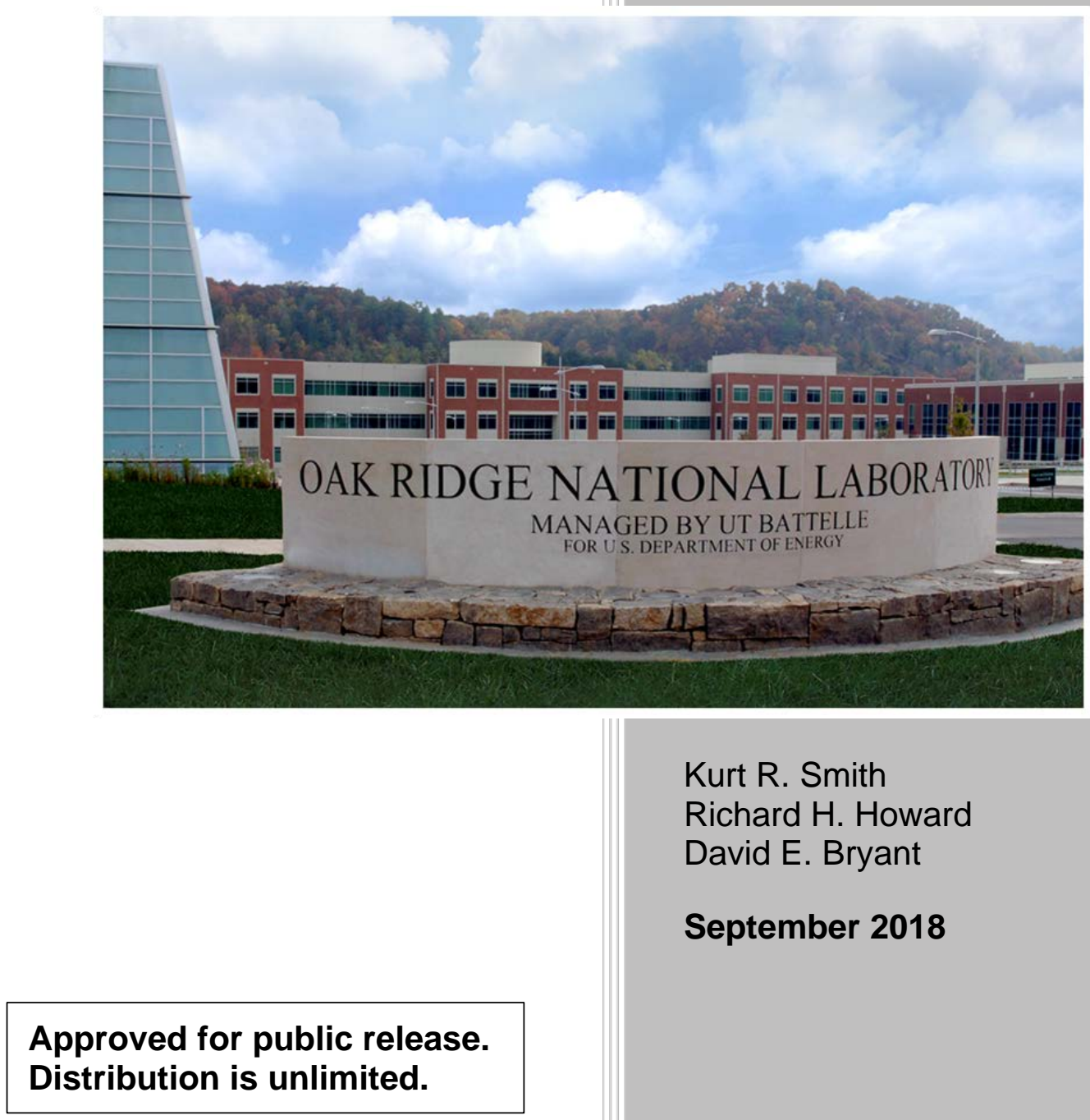

Kurt R. Smith

Richard H. Howard

David E. Bryant

September 2018 
Reactor and Nuclear Systems Division

\section{Destructive Testing of HFIR Irradiation Rabbit Capsules to Establish Containment Safety Limitations}

Kurt R. Smith

Richard H. Howard

David E. Bryant

Date Published: September 2018

Prepared by

OAK RIDGE NATIONAL LABORATORY

Oak Ridge, TN 37831-6283

managed by

UT-BATTELLE, LLC

for the

US DEPARTMENT OF ENERGY

under contract DE-AC05-00OR22725 



\section{CONTENTS}

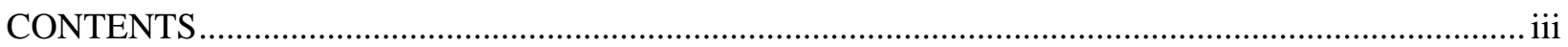

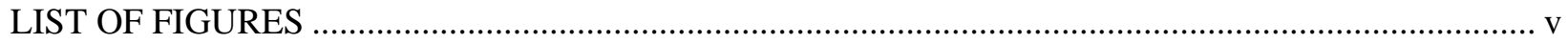

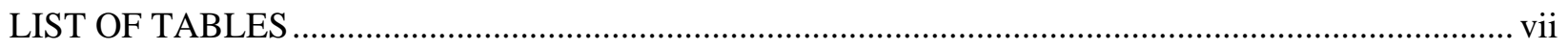

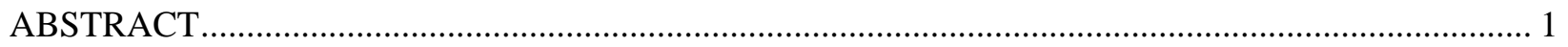

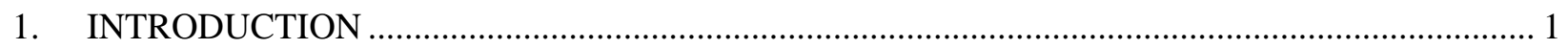

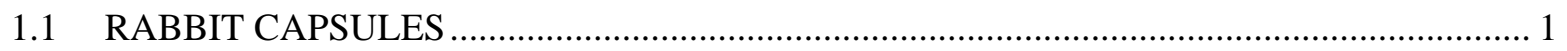

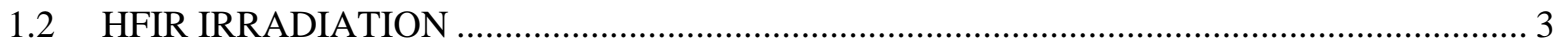

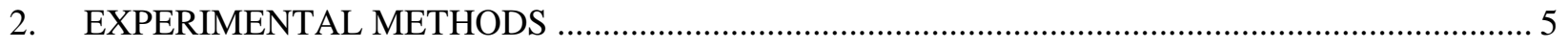

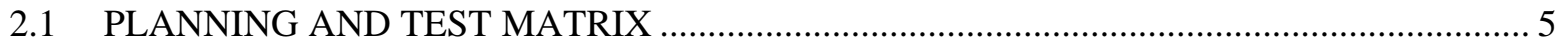

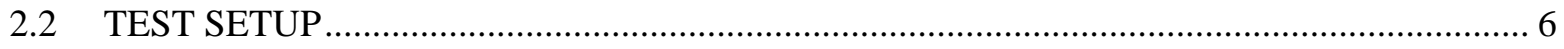

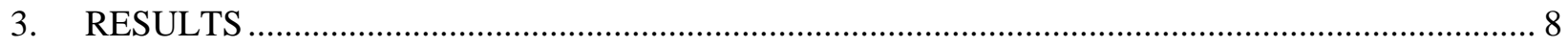

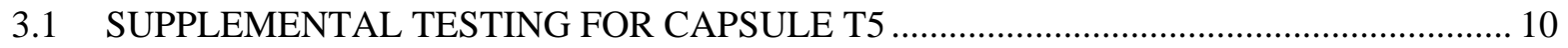

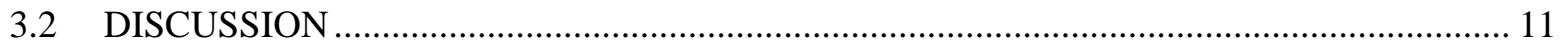

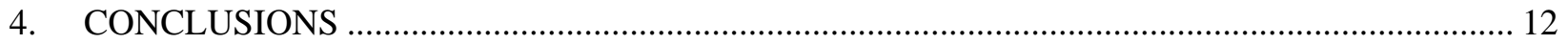

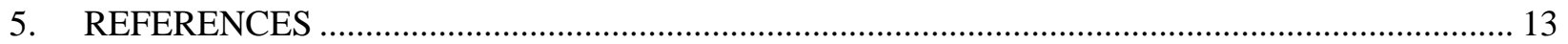

APPENDIX A. IRRADIATION CAPSULE CONTAINMENT EVALUATION PLAN......................... A-1

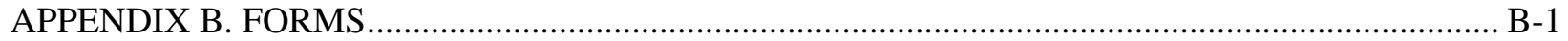





\section{LIST OF FIGURES}

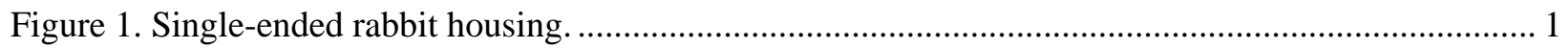

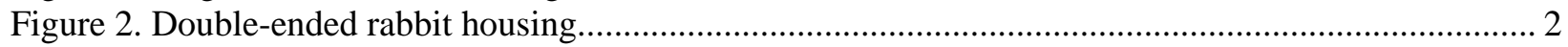

Figure 3. Exploded view of a typical rabbit capsule assembly ...................................................... 2

Figure 4. Cross section of a typical rabbit capsule assembly.................................................................... 3

Figure 5. Schematic (not to scale) showing transverse section view of HFIR core, reflector, and

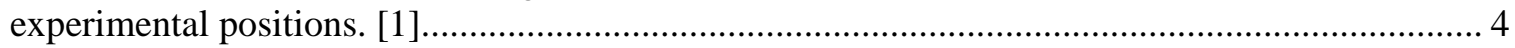

Figure 6. Single-ended capsule with/without button end cap. …............................................................ 5

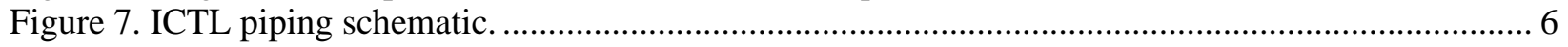

Figure 8. Rabbit burst test setup using the internal compression test loop................................................ 7

Figure 9. Failed capsules T1 (a), T2 (b), T3 (c), T4 (d), T7 (e), T8 (f), T9 (g), T10 (h), ......................... 9

Figure 10. Failed capsule T3 (a), Failed capsule T10 (b) …................................................................... 10

Figure 11. Failure in capsule T5, side view (a) and front view (b) ........................................................ 10

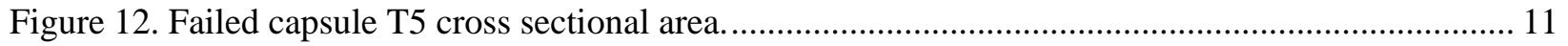





\section{LIST OF TABLES}

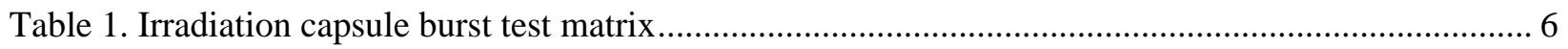

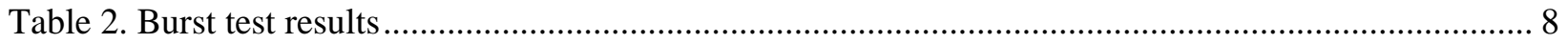

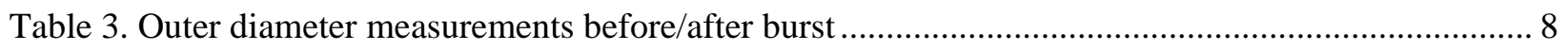

Table B-1 Instrument Calibration Log...................................................................................... B-2 



\begin{abstract}
Irradiation capsule containments, commonly referred to as rabbit capsules, are uninstrumented experiment capsules designed to facilitate irradiation of advanced materials, radioisotopes, and fuels in the High Flux Isotope Reactor (HFIR) at the Oak Ridge National Laboratory (ORNL). Rabbit capsules are versatile, as they are able to accommodate various shapes and sizes of specimens, and they can generally reach target temperatures between $200-1200^{\circ} \mathrm{C}$. The rabbit capsules' modes of failure under internal pressurization are important to characterize and understand, particularly when considering how failures can affect HFIR coolant flow channels. Destructive testing was completed on single- and doubleended thin-walled rabbit capsules to establish a mode of failure under internal pressure and to characterize elastic/plastic diametrical deformation. This report details the methods, results, and conclusions of the destructive testing.
\end{abstract}

\title{
1. INTRODUCTION
}

\subsection{RABBIT CAPSULES}

Rabbit capsules serve as a multipurpose irradiation platform. They are approximately 11 millimeters in diameter and 65 millimeters long. Various specimen geometries can be irradiated, including, but not limited to, tensile (round and flat), toughness, bend bar, and disk specimens. A broad range $\left(200-1200^{\circ} \mathrm{C}\right)$ of target temperatures can be achieved under HFIR's high neutron flux. Depending on the configuration of the internal assembly, a capsule can be single ended (blind hole) with one end cap, or double ended (thru hole) with one end cap on each end. All housing and end cap materials are aluminum. Figure 1 and Figure 2 depict these housings.

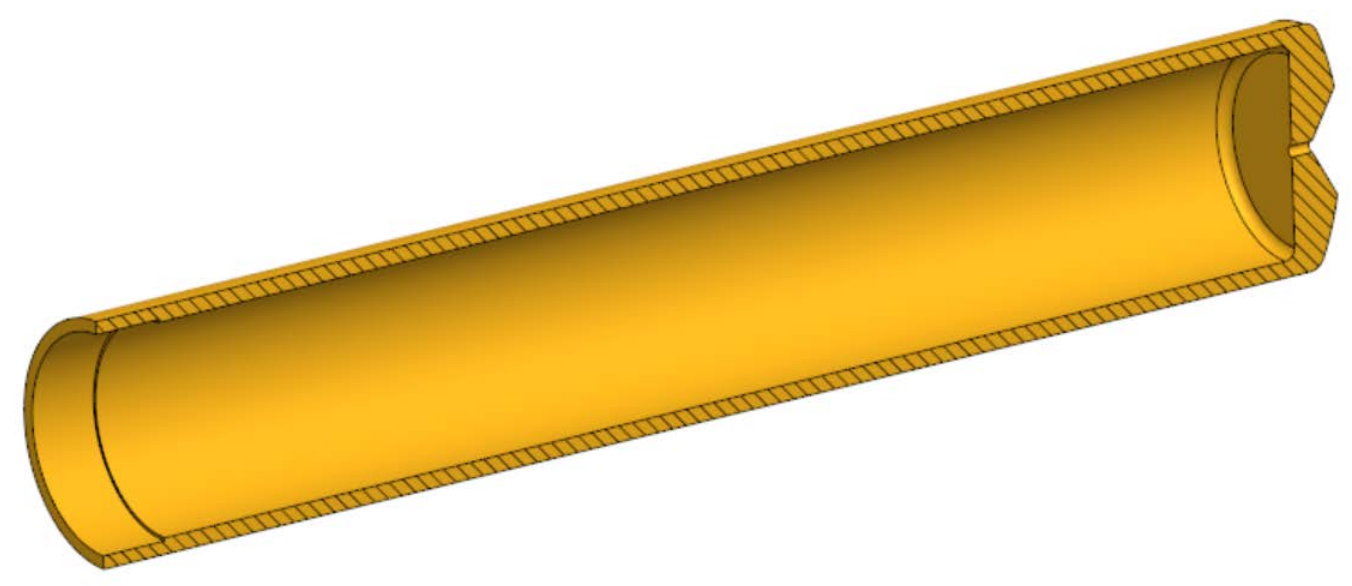

Figure 1. Single-ended rabbit housing. 


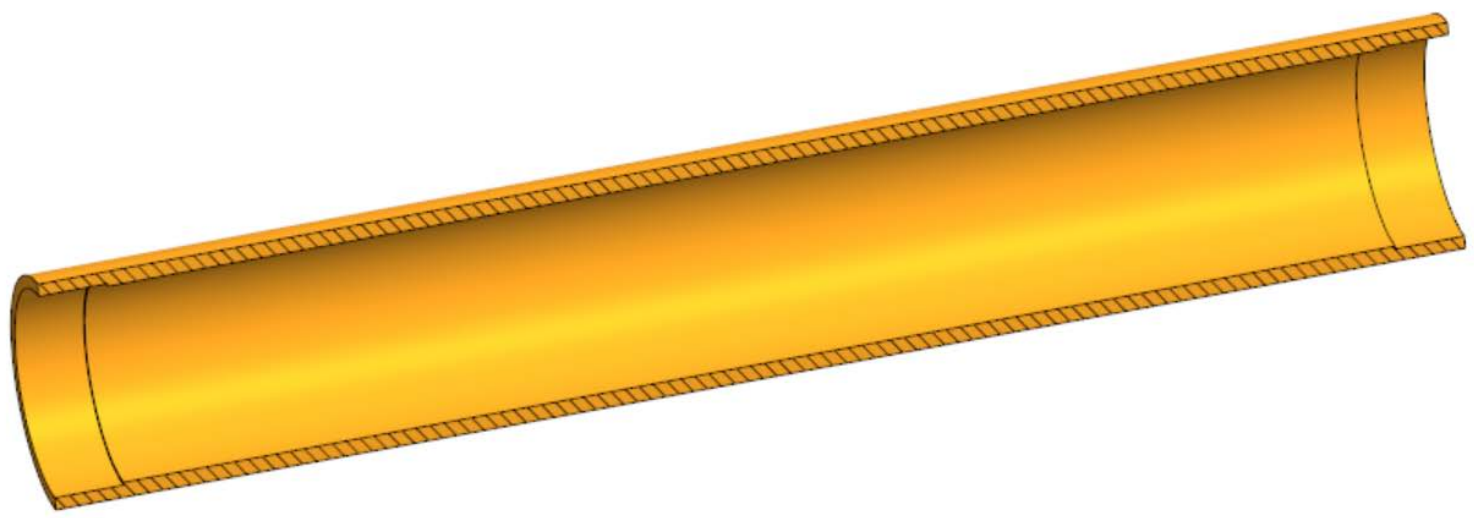

Figure 2. Double-ended rabbit housing.

The internals of the rabbit can change, depending on the particular experiment requirements, but they generally encompass a holder(s) containing specimens, silicon carbide passive thermometry, insulator/support disks, liners, centering thimbles, etc. The outer diameter of the holder, along with the inert backfill gas or gas mixture, can be adjusted to reach the desired target temperature. Once assembled, the housing and end cap(s) are welded using an electron beam welding process, followed by a gas tungsten arc weld to hermetically seal the capsule. Figure 3 and Figure 4 depict a general rabbit configuration.

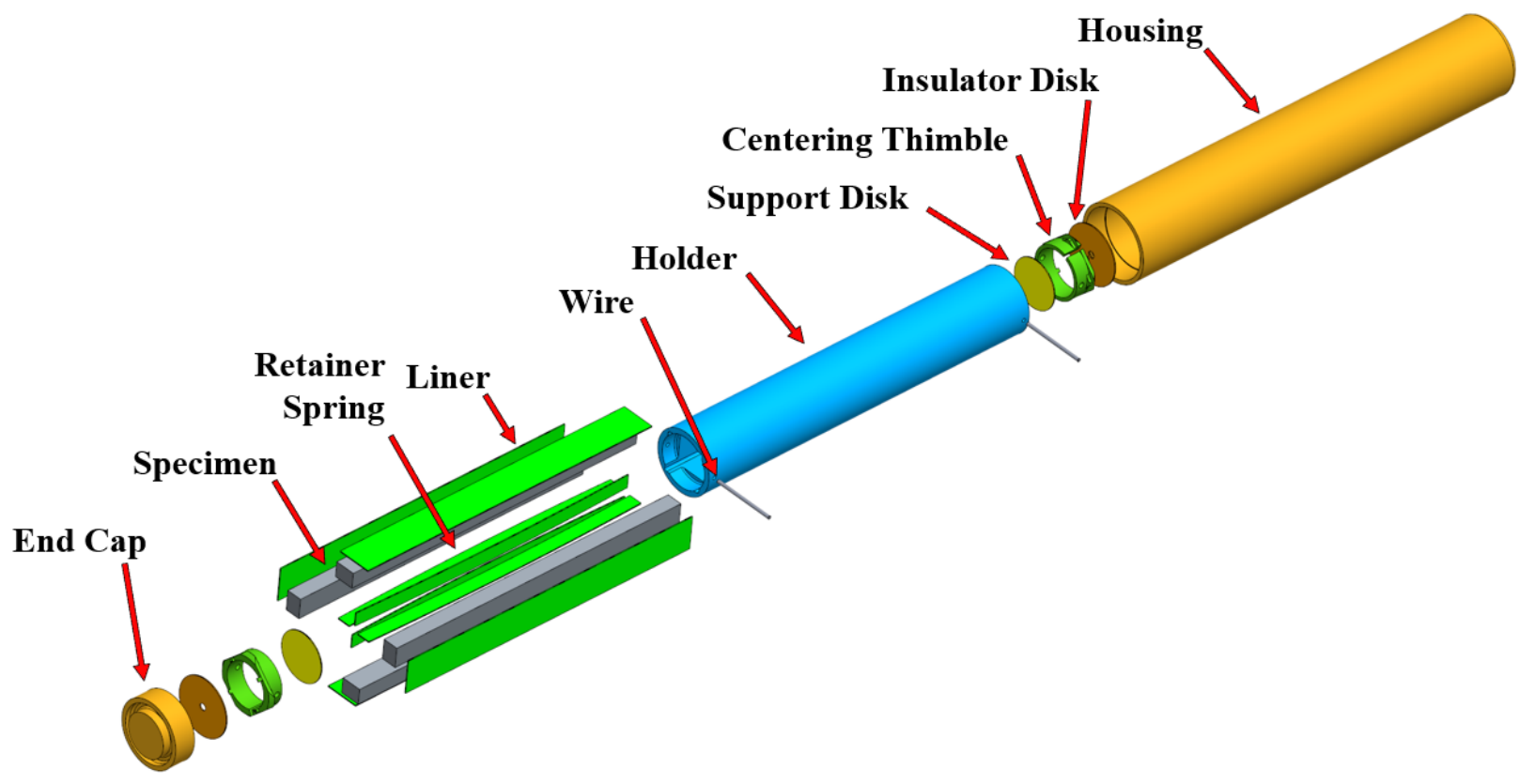

Figure 3. Exploded view of a typical rabbit capsule assembly. 


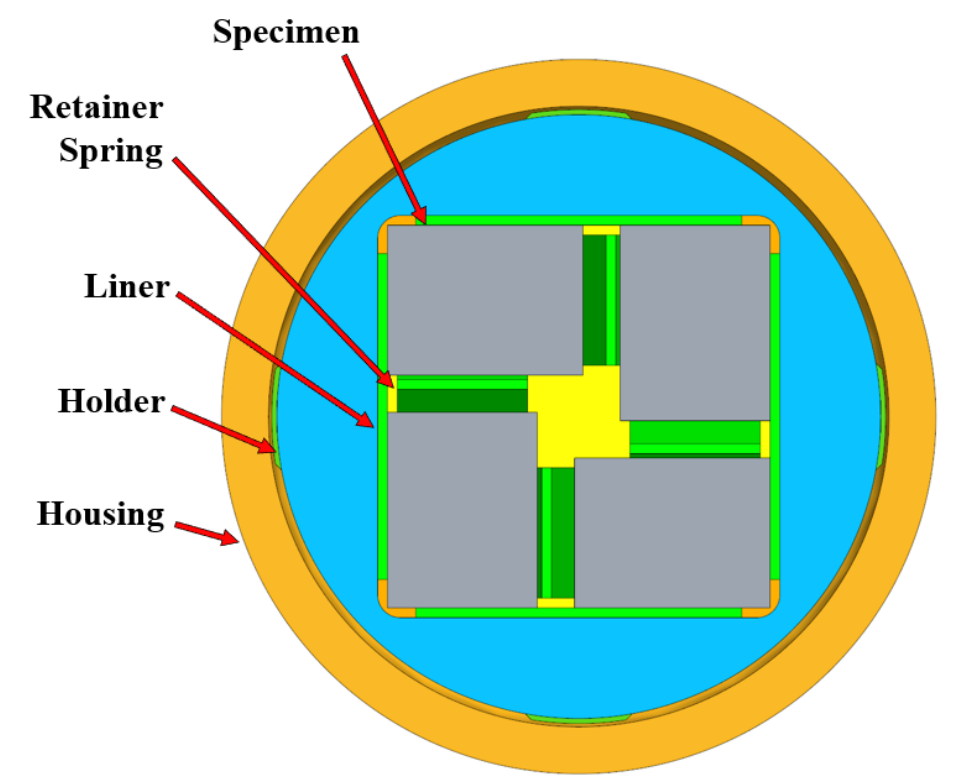

Figure 4. Cross section of a typical rabbit capsule assembly.

\subsection{HFIR IRRADIATION}

Rabbit capsules are irradiated in one of three flux trap irradiation facilities: The Peripheral Target Position (PTP) facility, the Target Rod Rabbit Holder (TRRH) facility, or the Hydraulic Tube (HT) facility. Figure 5 provides an illustration of the HFIR core. These facilities have unique enclosures that hold a stack of up to nine rabbit capsules. These enclosures also establish the coolant path and the ultimate heat sink boundary conditions for the experiments. More information regarding HFIR can be found at [1]. 


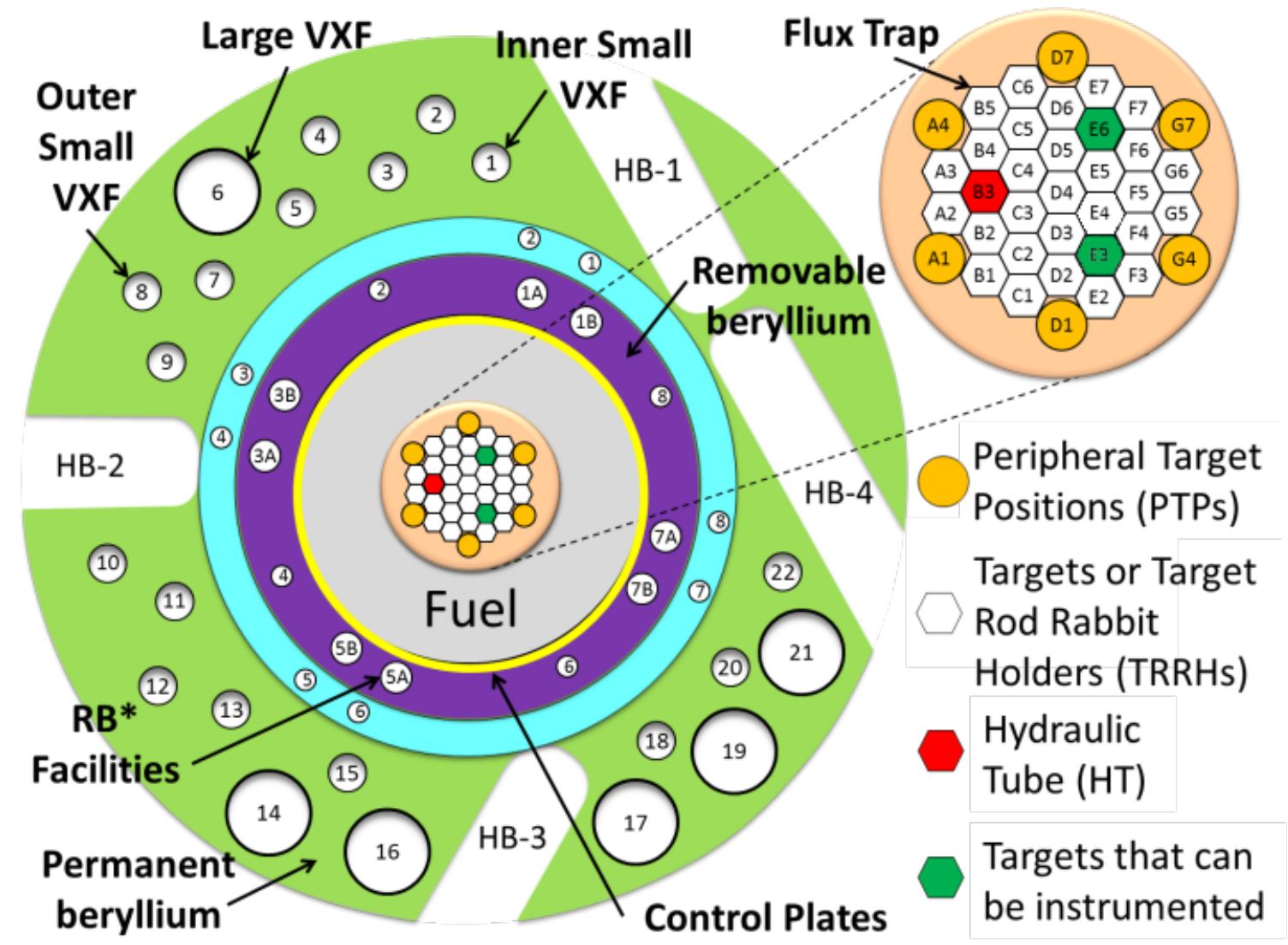

Figure 5. Schematic (not to scale) showing transverse section view of HFIR core, reflector, and experimental positions [1]. 


\section{EXPERIMENTAL METHODS}

\subsection{PLANNING AND TEST MATRIX}

Hydrostatic pressure tests were performed on 8 rabbit capsules to establish the limiting conditions for the aluminum capsule containment by (1) determining the containment failure mode under internal pressurization and (2) quantifying the maximum elastic/plastic deformation of the outside diameter before and after capsule failure. Capsule preparation and subsequent testing were performed according to the “Irradiation Capsule Containment Evaluation Plan” provided in APPENDIX A. A combination of singleand double-ended rabbits was tested. Capsule wall thicknesses were varied in some cases to consider dimensional variability due to machining tolerances. The end cap button is a design feature that protects the trepan weld of the rabbit by providing a nominal separation distance between the trepan weld and the neighboring capsules while they are stacked in the HFIR facility. The separation prevents frictional wear that can occur from oscillatory movement caused by flow-induced vibrations of the capsules in the reactor coolant. End caps with and without a sacrificial button material were included in the analysis. Figure 6 depicts both single-ended rabbit configurations.

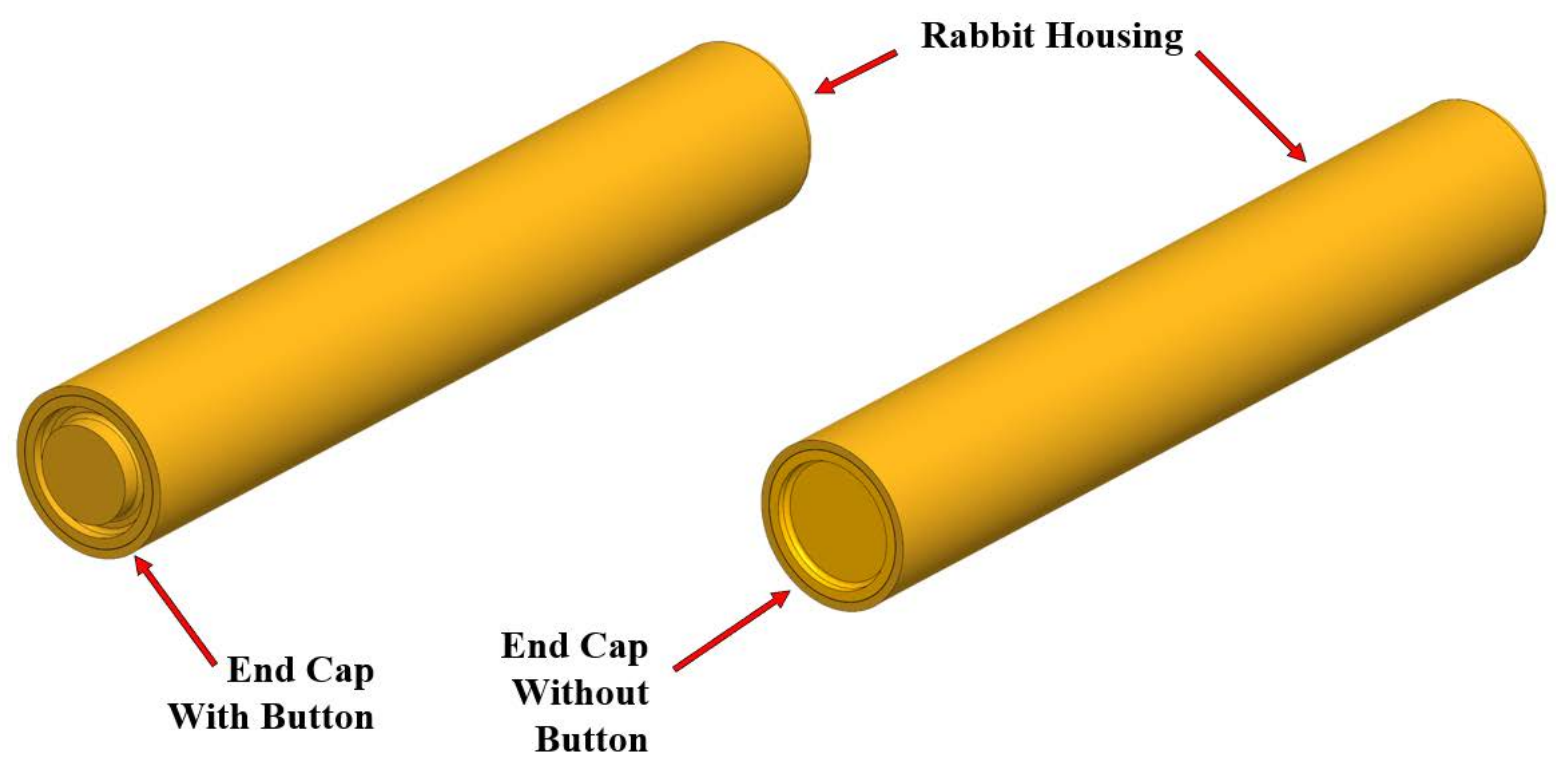

Figure 6. Single-ended capsule with/without button end cap.

The test matrix detailing capsule configurations, unique identification, and relevant drawings are provided in Table 1 below. T6 is omitted from the results due to nonconformances during the welding stage. The thinned wall of the housings was created by minimizing the outer diameters of the housings. This atypical size caused a loose fit in the weld fixture, severely defocusing the electron beam used to create the trepan weld. This resulted in an uncharacteristic, highly reinforced weld, rendering the burst results unreliable for this capsule. Capsule T5 also experienced a similar nonconformance, but it was tested regardless to establish a conservative test case. Results for this test are provided later in this document.

The irradiation capsules were prepared according to the typical Nuclear Experiments and Irradiation Testing Group's procedures and guidelines. All required dimensional inspections were completed, including the modified housings, and ORNL welding procedures followed. 
Table 1. Irradiation capsule burst test matrix

\begin{tabular}{lll}
\hline \multicolumn{1}{c}{$\begin{array}{c}\text { Capsule } \\
\text { identification }\end{array}$} & \multicolumn{1}{c}{ Description } & \multicolumn{1}{c}{ Drawing } \\
\hline T1, T2 & $\begin{array}{l}\text { Single ended, end cap w/ button, } \\
\text { nominal dimensions } \\
\text { Single ended, end cap w/ button, }\end{array}$ & X3E020977A633, Rev 1 \\
T3, T4 & $\begin{array}{l}\text { within tolerance, minimum wall } \\
\text { thickness (.682mm wall) }\end{array}$ & X3E020977A633, Rev 1 \\
& $\begin{array}{l}\text { Single ended, end cap w/ button, out } \\
\text { of tolerance, thinned wall (.610mm }\end{array}$ & X3E020977A633, Rev 1 \\
T5, T6 & $\begin{array}{l}\text { Wall) } \\
\text { Single ended, end cap w/o button, }\end{array}$ & X3E020977A633, Rev 0 \\
T7, T8 & $\begin{array}{l}\text { Dominal dimensions } \\
\text { button, nominal dimensions }\end{array}$ & X3E020977A646, Rev 0 \\
T9, T10 & & \\
\hline
\end{tabular}

\subsection{TEST SETUP}

The internal compression test loop (ICTL) was used to perform the destructive testing. The ICTL was developed to hydrostatically load test capsules to various internal pressures to set bounding pressures for capsule failure, plastic deformation, operating pressure, etc. This loop includes a manually operated pump, a pressure relief valve, a calibrated gauge, a bleeder valve, and the required plumbing. The piping schematic in Figure 7 below provides more detail.

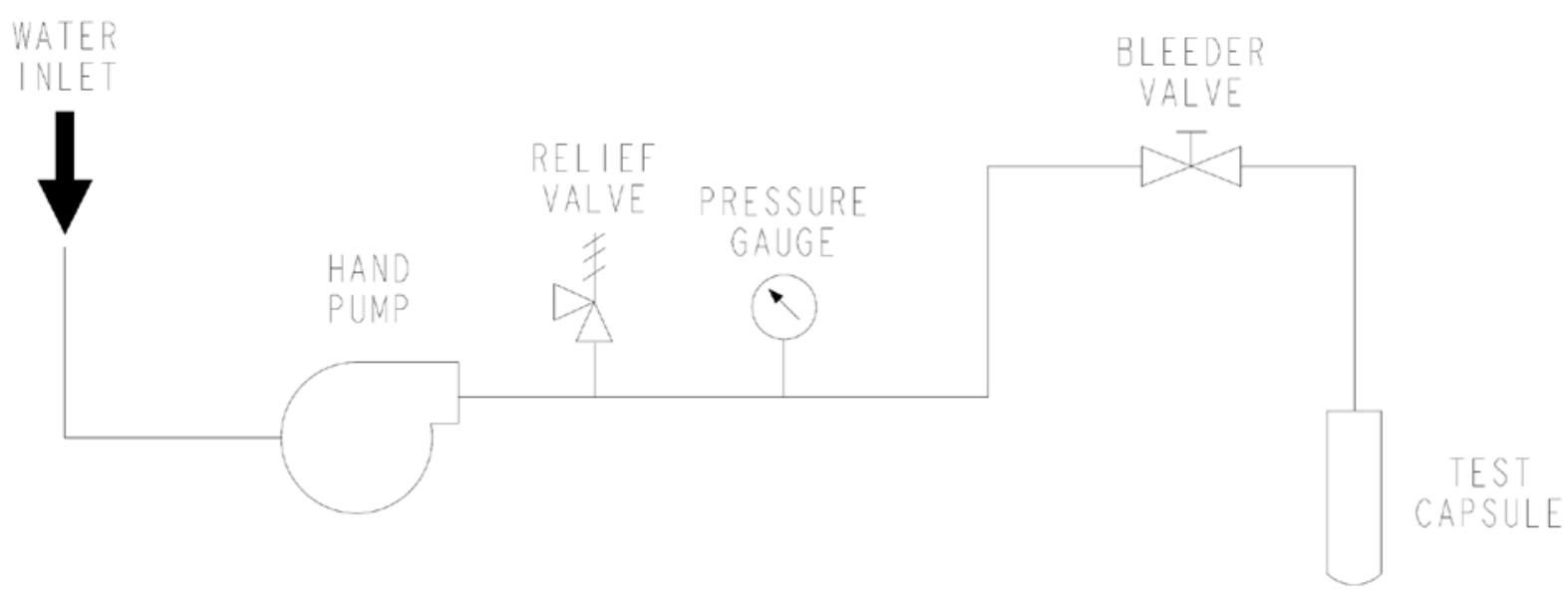

Figure 7. ICTL piping schematic.

A Mitutoyo plunge-style digital indicator was used to take measurements of the outer diameter during the test. This was done to monitor deformations at fixed pressure intervals during the test and to measure maximum deformation at failure. It was assumed that the worst-case deformation would occur in the middle of the capsule, where the material is least supported. Therefore, this is the location used for the measurements. The setup with ICTL and the digital indicator is shown in Figure 8. An instrument calibration log for the indicator and pressure gauge is included in APPENDIX B. 
A safety shield is placed around the capsule to be tested to protect the personnel operating the system. A hole was machined in the shield to allow the indicator to properly align onto the test capsules without receiving any interference from the shield. The system was allowed to stabilize before the indicator readings were recorded to minimize measurement error introduced from the compliance of the fixture.

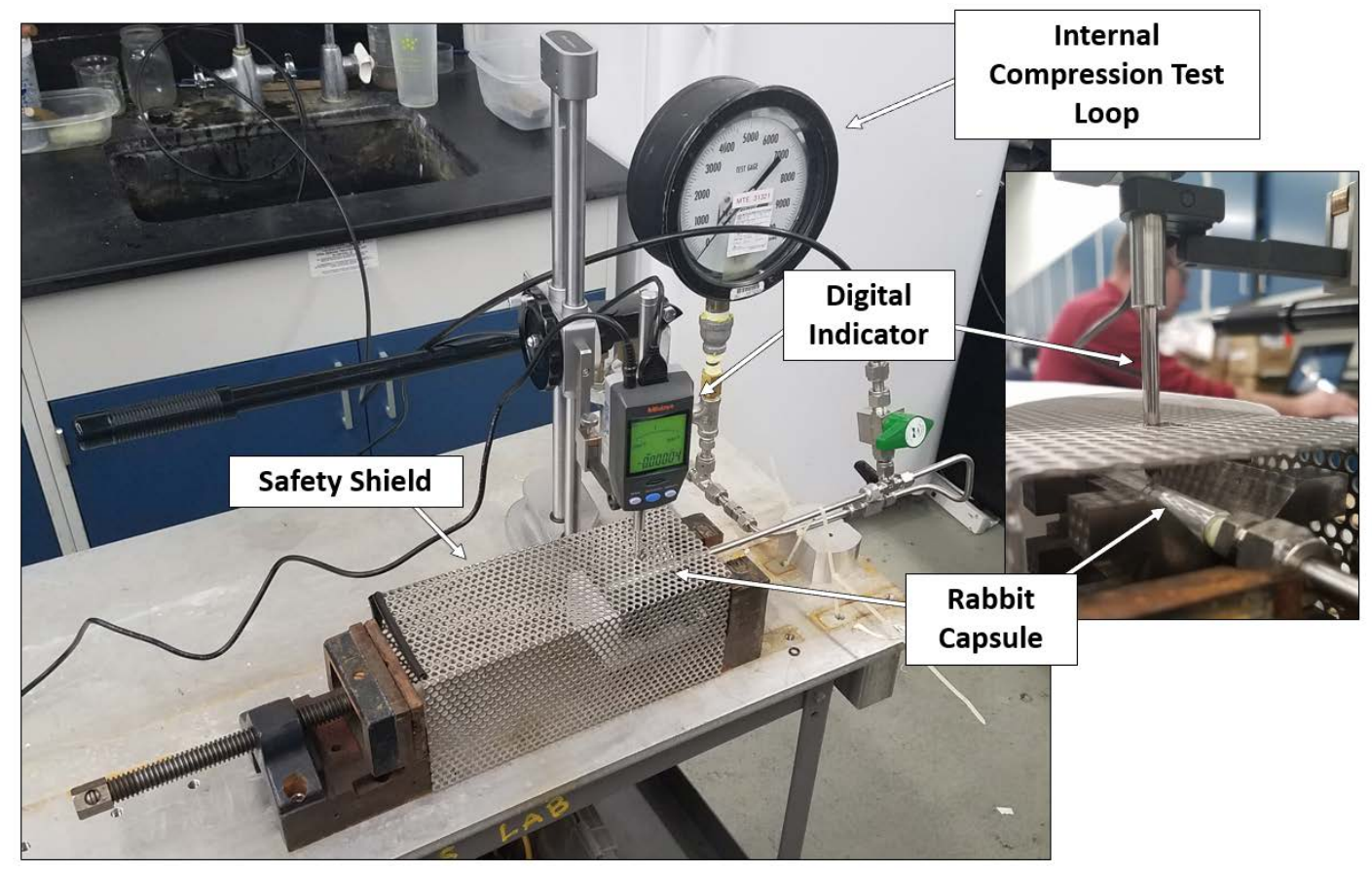

Figure 8. Rabbit burst test setup using the internal compression test loop. 


\section{RESULTS}

Table 2 presents the indicator readings and failure pressures for rabbit capsules T1-T4 and T7-T10. Most capsules, with some exceptions, exhibited similar failure modes. Weld shearing damage occurred at the end cap-to-housing trepan weld zone, resulting in a portion of the end cap separating from the housing. This creates a hinge with the intact weld material and bends the end cap outward approximately $45^{\circ}$. See Figure 9 for failed rabbits T1-T4 and T7-T10.

Table 2. Burst test results

\begin{tabular}{|c|c|c|c|c|c|c|c|}
\hline \multirow{3}{*}{ Capsule identity } & \multicolumn{5}{|c|}{ Pressure intervals (PSI) ( \pm 50 psi) } & \multirow{3}{*}{$\begin{array}{c}\text { Burst } \\
\text { pressure } \\
\text { (PSI) }\end{array}$} & \multirow{3}{*}{$\begin{array}{c}\text { Maximum } \\
\text { deformation } \\
\text { at mid-surface } \\
(\mathbf{m m})\end{array}$} \\
\hline & 0 & 500 & 1,000 & 1,500 & 2,000 & & \\
\hline & \multicolumn{5}{|c|}{ indicator reading (mm) } & & \\
\hline $\mathbf{T 1}$ & 0 & 0 & 0.04 & 0.05 & 0.06 & 5,000 & 0.08 \\
\hline $\mathbf{T} 2$ & 0 & 0 & 0 & 0 & 0 & 4,300 & 0.04 \\
\hline T3 & 0 & 0 & 0 & 0 & 0.01 & 5,200 & 0.05 \\
\hline T4 & 0 & 0 & 0.01 & 0.01 & 0.01 & 5,800 & 0.03 \\
\hline T7 & 0 & 0 & 0 & 0 & 0.01 & 5,500 & 0.02 \\
\hline T8 & 0 & 0 & 0 & 0 & 0.01 & 4,500 & 0.02 \\
\hline T9 & 0 & 0 & 0 & 0.01 & 0.01 & 5,600 & 0.12 \\
\hline T10 & 0 & 0 & 0.01 & 0.01 & 0.01 & 5,000 & 0.06 \\
\hline
\end{tabular}

Measurements of the overall outer diameters across the full length of the failed capsules were completed following testing. These results are compared to the pretested measurements in Table 3 below.

Table 3. Outer diameter measurements before/after burst

\begin{tabular}{lcccccccc} 
& T1 & T2 & T3 & T4 & T7 & T8 & T9 & T10 \\
\hline $\begin{array}{l}\text { Outer diameter, after } \\
\text { testing (mm) }\end{array}$ & 11.19 & 11.09 & 11.23 & 11.22 & 11.10 & 11.05 & 11.03 & 11.54 \\
\hline $\begin{array}{l}\text { Outer diameter, before } \\
\text { testing (mm) }\end{array}$ & 10.95 & 10.95 & 10.92 & 10.91 & 10.95 & 10.96 & 10.96 & 10.96 \\
\hline
\end{tabular}


(a)

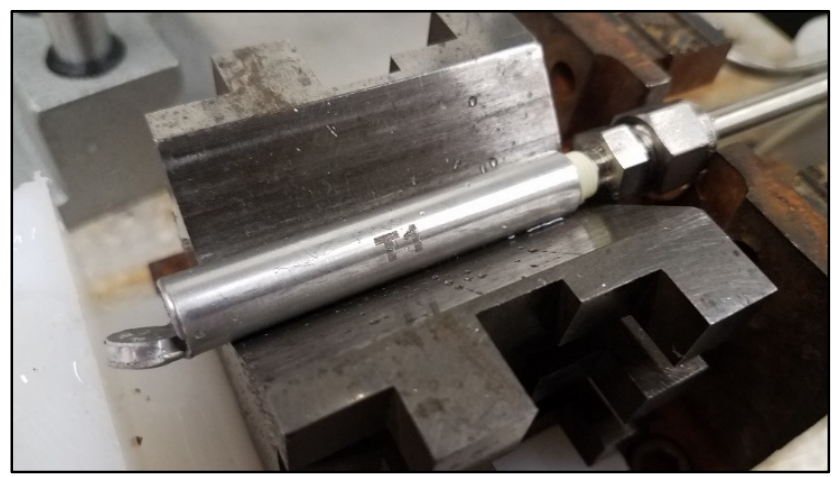

(b)

(c)

(d)
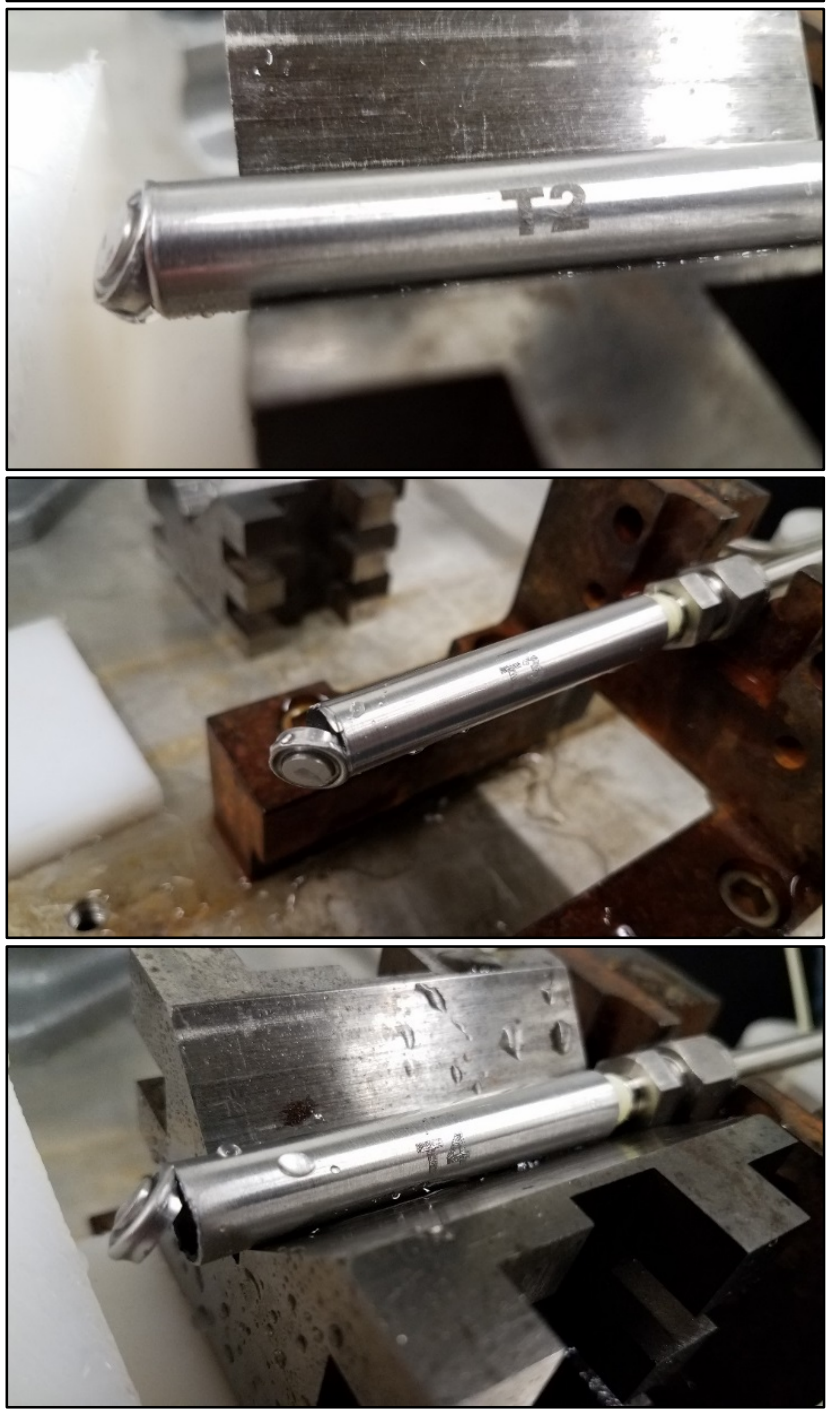

(e)

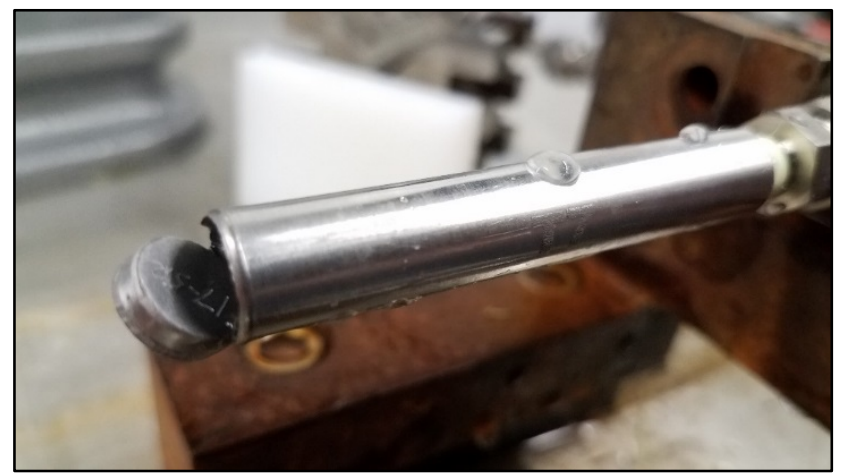

(f)

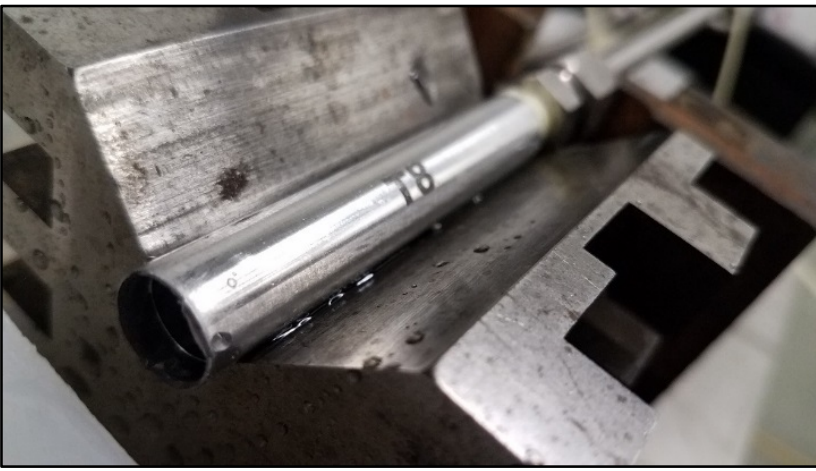

(g)

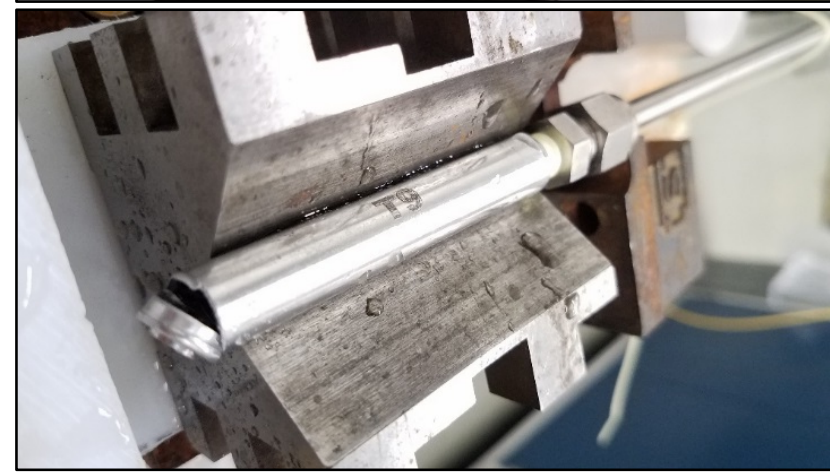

(h)

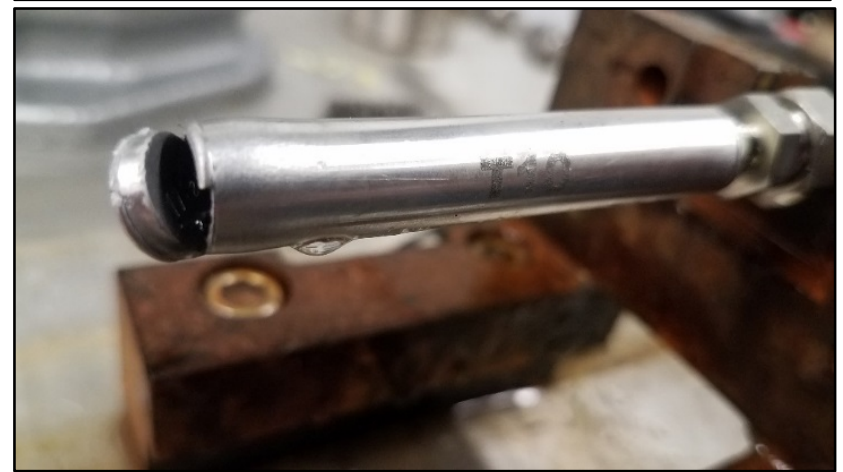

Figure 9. Failed capsules T1 (a), T2 (b), T3 (c), T4 (d), T7 (e), T8 (f), T9 (g), T10 (h).

The increased diameter is due to two factors: (1) plastic deformation in the outer diameter of the housing and (2) the trepan weld shear, which bent weld material outward. Both factors consistently occur locally in the trepan weld area. Examples of this are shown in Figure 10. Capsule T10 exhibited unique behavior compared to other capsules tested. Although the end cap failed as expected, noticeable plastic deformation was present at the outer diameter of the housing near the trepan weld, as illustrated in 
Figure 10. Variability in weld parameters, the heat affected zone, and the dimensional eccentricities are among the factors contributing to this behavior.

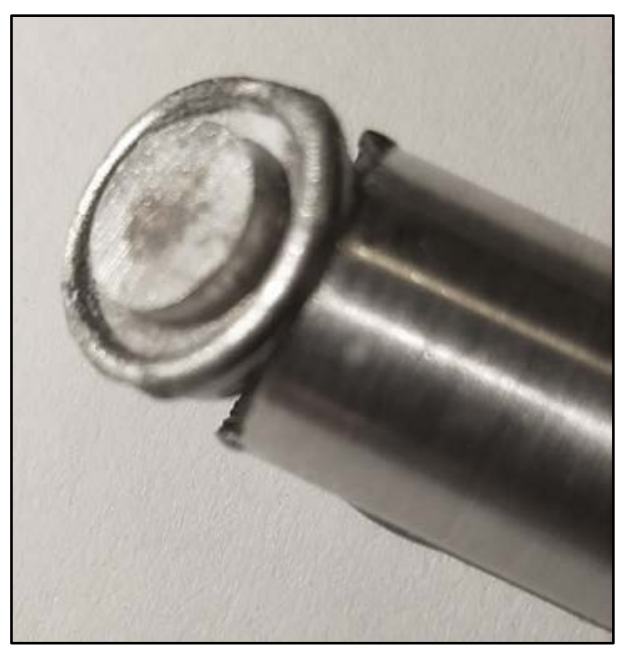

(a)

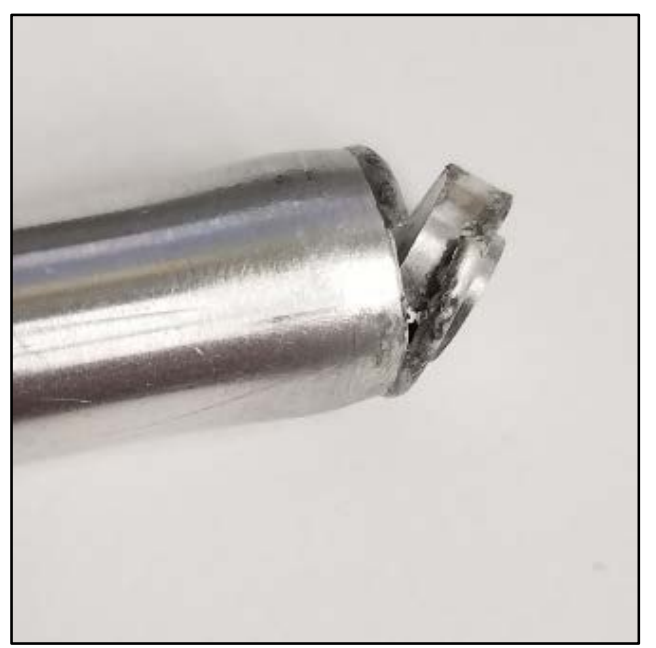

(b)

Figure 10. Failed capsule T3 (a), Failed capsule T10 (b).

\subsection{SUPPLEMENTAL TESTING FOR CAPSULE T5}

As discussed in Section 2.1, capsule T5 was omitted from the previous section. An artificially reinforced trepan weld is expected to have a significant impact on the failure mode of the capsule. This test demonstrates that the artificially reinforced trepan weld caused the failure mechanism to move from the trepan weld to the housing wall. The results of this test showed a ballooned outer diameter in the trepan weld region. Failure did not occur at the end cap and weld as usual, but instead, it blew out the side wall at 4,300 psi.

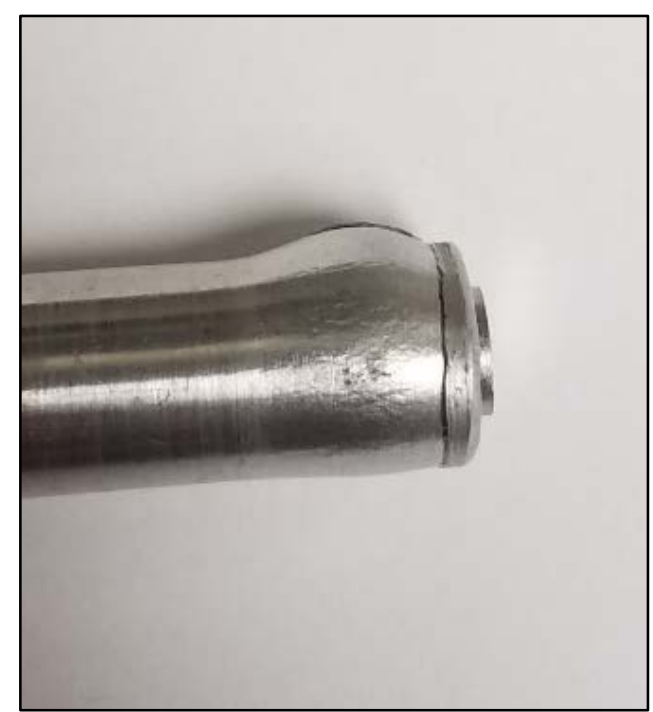

(a)

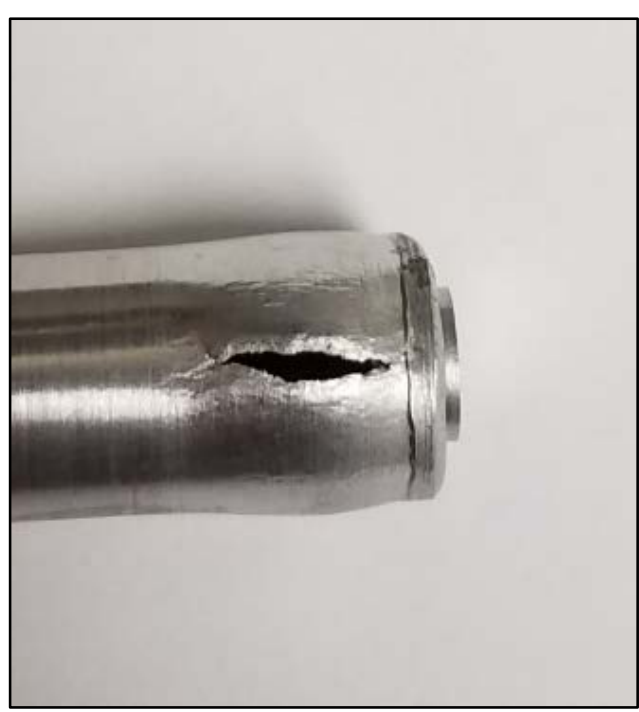

(b)

Figure 11. Failure in capsule T5, side view (a) and front view (b). 


\subsection{DISCUSSION}

When considering irradiation experiments in the HFIR, one significant concern is whether a flow channel can be become blocked from an unexpected pressurization event within an irradiation capsule. This work demonstrates that the pressure relief mechanism exists at the housing-to-end cap electron beam welded joint for a rabbit containment that meets drawing specifications and is properly assembled/welded per ORNL procedures. It was also shown that no significant change in the overall diameter of the capsule occurred during capsule failure.

To establish baseline criteria for the maximum allowable apparent diameter in this HFIR flow channel, the capsule's overall cross sectional areas can be compared to a beryllium spacer that is commonly used in the target rod holder. Based on the engineering drawing, the cross-sectional area of the spacer is calculated at $122.7 \mathrm{~mm}^{2}$. For the case of T5, which exhibited the most severe containment deformation, the capsule containment deformed to an approximate area of $109.0 \mathrm{~mm}^{2}$ (see Figure 12). Therefore, the maximally deformed housing from this set of tests is still bounded by the normal outer diameter of the beryllium spacer.

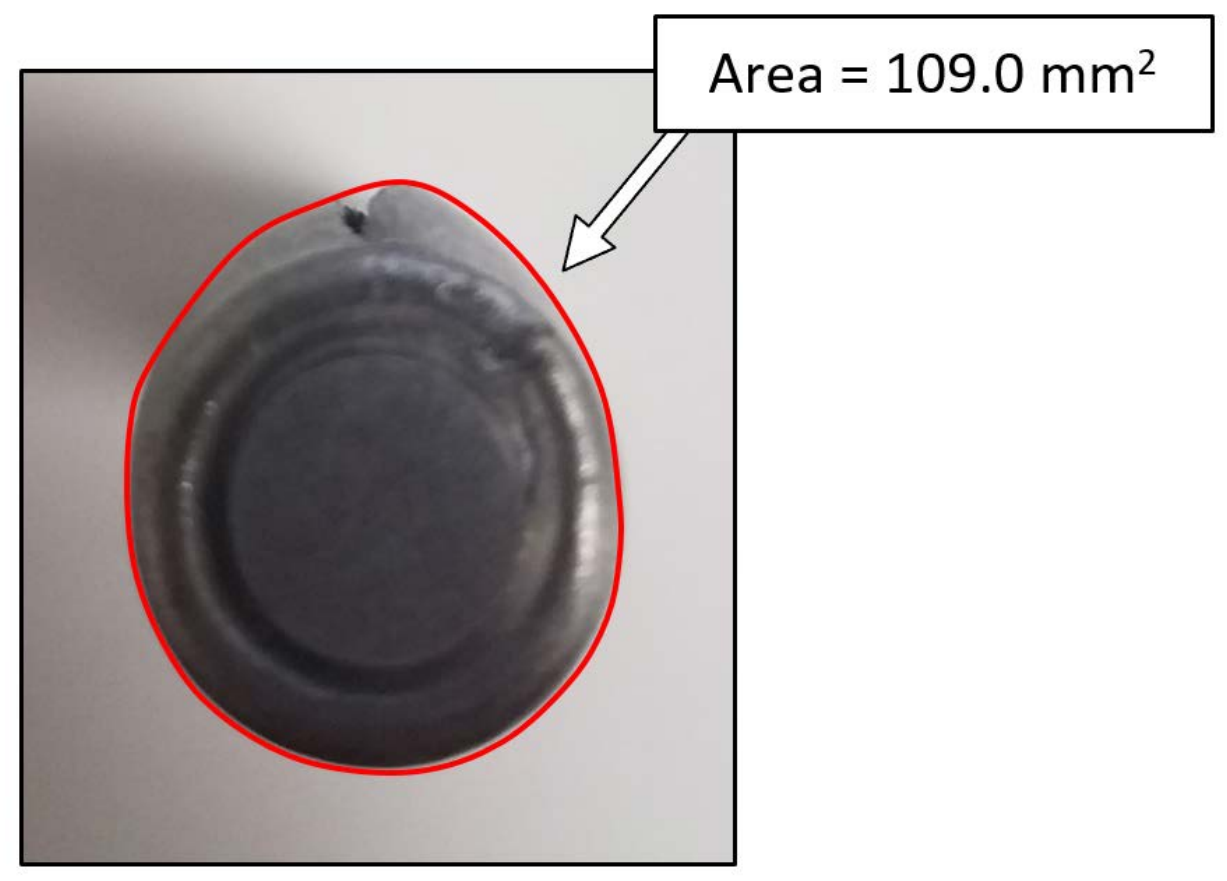

Figure 12. Failed capsule $\mathbf{T} 5$ cross sectional area. 


\section{CONCLUSIONS}

This work summarizes test results for a combination of single- and double-ended rabbits using end caps with and without sacrificial button material. Overall, with some exceptions, comparable failure modes were displayed. The end cap to the housing trepan weld exhibited shear failure, with the cap partially separating from the housing at pressures ranging from 4,300-5,800 psi. A negligible amount of plastic deformation occurred during pressurization at the middle of the capsule, and the maximum change in overall diameter measured after the test was 0.58 millimeters for capsule T10. This change in diameter was primarily localized in the trepan region of the rabbit. 


\section{REFERENCES}

[1] Oak Ridge National Laboratory, "High Flux Isotope Reactor," [Online]. Available: https://neutrons.ornl.gov/hfir. 

APPENDIX A. IRRADIATION CAPSULE CONTAINMENT EVALUATION PLAN 


\section{Irradiation Capsule Containment Evaluation Plan}

Date

Prepared By:
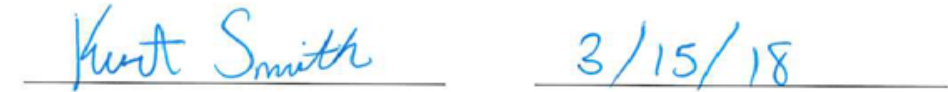

Approved By:
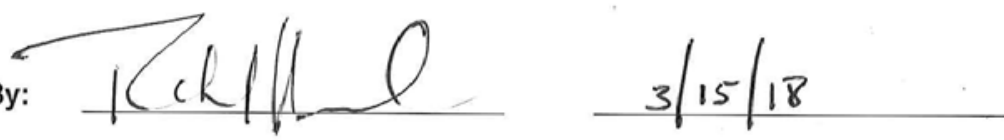

1. Scope

This document provides guidance for the burst testing of the irradiation capsule containment, also known as rabbit housing. This guidance document includes:

- A list of recommended equipment

- A test matrix identifying specific capsule configurations to be tested

- Instructions for preparing the capsules and equipment

- Recommended order of operations for performing the test

- Documentation to be used for recording experimental data

\section{Engineering Drawings}

The drawings provide further guidance on the external configuration of the irradiation capsule. The list includes:

- X3E020977A633 Rev. 0 \& 1 - Target Capsule Housing Assembly

- X3E020977A634 Rev. A \& B - Target Capsule Housing/End Cap Details

- X3E020977A646 Rev. 0 - Target Capsule Housing/End Cap Assembly

- X3E020977A647 Rev. 0 - Target Capsule Housing/End Cap Details 
Irradiation Capsule Containment Evaluation Plan

Thermal Hydraulics \& Irradiation Engineering Group

Revision No: 0

Reactor and Nuclear Systems Division

Date: February 2, 2018

Oak Ridge National Laboratory

Page 2 of 5

\section{Recommended Equipment}

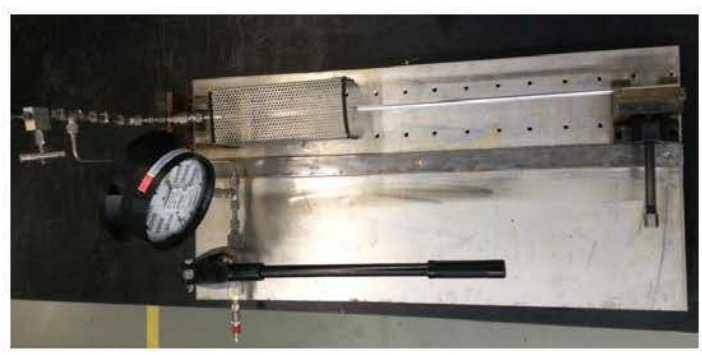

Internal compression test loop

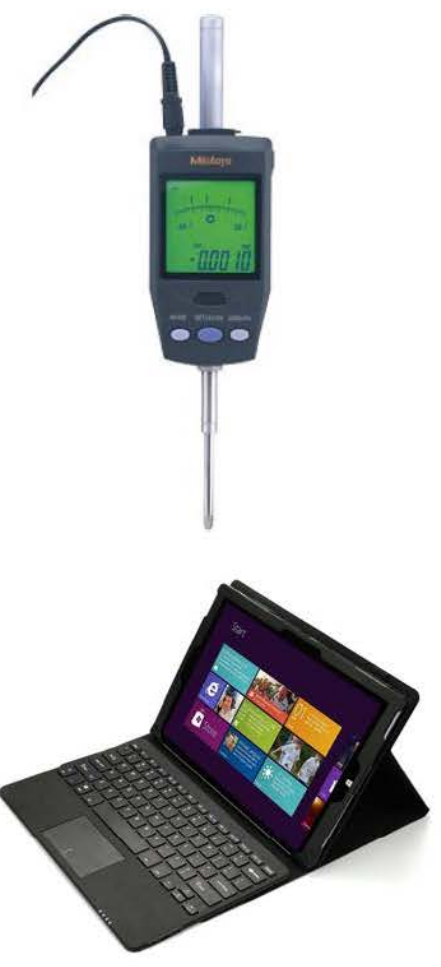

Digital indicator with stand

PC or data collection device 


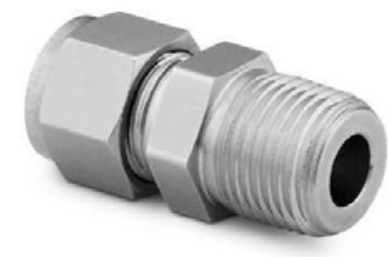

$1 / 4$ " $\times 1 / 8$ " MNPT male connector (Swagelok SS-400-1-2)

\section{Capsule and Equipment Notes}

\subsection{Irradiation Capsule}

The irradiation capsules are to be prepared according to the typical Irradiation Engineering Group's procedures and guidelines. All required dimensional inspections should be completed and ORNL welding procedures followed. The testing will be performed in conditions assumed to be room temperature. The capsules used for testing will include a single ended housing with nominal dimensions and ones with maximum/minimum tolerances that create a minimum wall thickness part. Six of these capsules will use an end cap with a button top, while two others will use an end cap with no button. Additionally, two double ended capsules with nominal dimensions will also be tested. The goal here is to compare the capsules using the end cap with a button to the end caps without a button. Table 2 in Appendix A provides specific guidance for this.

The single ended irradiation capsule housings will be prepared in accordance with drawing X3E020977A634- Target Capsule Housing/End Cap Details, Rev A and B, and assembled/welded according to drawing X3E020977A633 - Target Capsule Housing Assembly, Rev 0 and 1. The double ended capsule parts will be prepared in accordance with drawing X3E020977 A647 - Target Capsule Housing/End Cap Details, Rev 0, and assembled/welded according to drawing X3E020977A646 - Target Capsule Housing Assembly, Rev 0. This is with the exception that the seal weld will not be performed on all capsules. All relevant part and assembly inspections should be completed according to RRD-JS-24 for in-process collection of information. Each capsule should be clearly marked with unique identification using the IDs provide in Table 2.

\subsection{Internal Compression Test Loop}

The internal compression test loop (ICTL) was developed to hydrostatically load test capsules to various internal pressures in order to set bounding pressures for capsule failure, plastic deformation, operating pressure, etc. This loop includes a manually operated pump, pressure relief valve, calibrated gauge, bleeder valve, and required plumbing. See the piping schematic in Figure 1 below for more detail. 


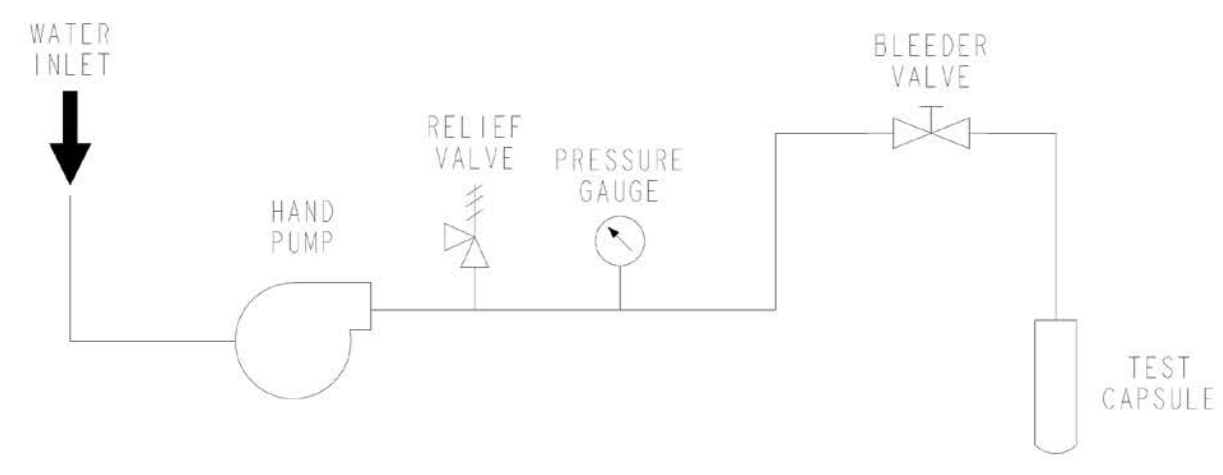

Figure 1. Internal compression test loop piping schematic

\section{Performing Burst Testing}

The information below outlines the process in which a successful burst test is completed. This covers data collection, proper capsule support, pressure intervals, and ultimately what can be expected at failure. Table 3 should be used to record specific data, i.e., capsule identity, diameter, and burst pressure. Pictures before and after testing should be taken of the overall capsules and of the trepan weld zones, making sure the identification markings on the capsule are clear in each picture. A digital indicator will be used to take a real-time measurement of the capsule diameter as the pressure is increased. A data collection device will be used to record and save the data during testing for processing later. Instrument calibration information should be recorded using Table 1 provided in Appendix A.

\subsection{Test Preparation}

5.1.1.

Prepare an irradiation capsule as described in section 4.1.

The capsule should be drilled and tapped for a 1/8" MNPT thread. Install a 1/4" x 1/8" MNPT Male Connector (Swagelok SS-400-1) into the capsule. 
Irradiation Capsule Containment Evaluation Plan

Thermal Hydraulics \& Irradiation Engineering Group

Revision No: 0

Reactor and Nuclear Systems Division

Date: February 2, 2018

Oak Ridge National Laboratory

Page 5 of 5

The ICTL requires a separate water source to operate. Once the capsule is properly installed and the water source is established, the loop must be purged of all air. This is

5.1 .4 accomplished by opening the bleeder valve and running water through the loop until air is no longer ejected from the valve outlet. Once this task is complete, the bleeder valve should be closed and the loop is ready for operation.

5.1.6 Position an appropriately sized V-block underneath the rabbit to minimize movement of the capsule and provide support during the test.

The digital indicator should be placed on a suitable holder and firmly fixed in place within reach of the irradiation capsule to be tested. Position the probe on the capsule such that any diametrical change in the housing is picked up by the indicator.

Install the blast shield over the capsule. The blast shield should allow entry of the indicator tip without obstructing the measurement and hindering the effectiveness of the shield.

Attach digital indicator to the data collection device and ensure the equipment is functioning properly. Zero the indicator reading once the device is positioned properly.

\subsection{Performing the Burst Test}

5.2.1.

Pressure should be approximately applied in the intervals given in Table 3.Following each interval, allow the system to settle before recording the indicator and actual pressure reading. Use Table 3 to record the data. Continue these steps until the system reaches 2000 psi.

After recording data for the $2000 \mathrm{psi}$ interval, apply pressure to the capsule until failure occurs. Record the pressure reading at the time of failure and the maximum plastic deformation on the $\mathrm{OD}$ of the rabbit.

Failure of the capsule is expected to be located in the trepan weld zone. Carefully remove the failed capsule and take photos of the failed region. The ID markings on the capsule should be clearly visible in the photo. 
Irradiation Capsule Containment Evaluation Plan

Thermal Hydraulics \& Irradiation Engineering Group

Revision No: 0

Reactor and Nuclear Systems Division

Date: February 2, 2018

Oak Ridge National Laboratory

Page A-1 of 9

APPENDIXA

TABLES AND DRAWINGS 
Irradiation Capsule Containment Evaluation Plan

Thermal Hydraulics \& Irradiation Engineering Group

Revision No: 0

Reactor and Nuclear Systems Division

Date: February 2, 2018

Oak Ridge National Laboratory

Page A-2 of 9

\begin{tabular}{|l|l|l|l|}
\hline Instrument & Serial Number & Calibration Number & Calibration Date \\
\hline & & & \\
\hline & & & \\
\hline & & & \\
\hline & & & \\
\hline & & & \\
\hline
\end{tabular}

Table 1. Instrument Calibration Documentation

\begin{tabular}{|c|c|c|c|}
\hline $\begin{array}{c}\text { Capsule } \\
\text { Identification }\end{array}$ & Description & Drawing & Quantity \\
\hline T1, T2 & Single ended, nominal dimensions & $\begin{array}{c}\text { X3E020977A633, } \\
\text { Rev 1 }\end{array}$ & 2 \\
\hline T3, T4 & $\begin{array}{c}\text { Single ended, within tolerance, minimum wall } \\
\text { thickness (.682mm wall) }\end{array}$ & $\begin{array}{c}\text { X3E020977A633, } \\
\text { Rev 1 }\end{array}$ & 2 \\
\hline T5, T6 & Single ended, out of tolerance, thinned wall \\
(.610mm wall) & $\begin{array}{c}\text { X3E020977A633, } \\
\text { Rev 1 }\end{array}$ & 2 \\
\hline T7, T8 & Single ended, nominal dimensions & $\begin{array}{c}\text { X3E020977A633, } \\
\text { Rev 0 }\end{array}$ & 2 \\
\hline T9, T10 & Double ended rabbit, nominal dimensions & $\begin{array}{c}\text { X3E020977A646, } \\
\text { Rev 0 }\end{array}$ & 2 \\
\hline
\end{tabular}

Table 2. Irradiation Capsule Burst Test Matrix 
Irradiation Capsule Containment Evaluation Plan

Thermal Hydraulics \& Irradiation Engineering Group

Revision No: 0
ebruary 2, 2018

Reactor and Nuclear Systems Division

Oak Ridge National Laboratory

\begin{tabular}{|c|c|c|c|c|c|c|c|c|}
\hline \multirow{2}{*}{$\begin{array}{l}\text { CAPSULE } \\
\text { IDENTITY }\end{array}$} & & \multicolumn{5}{|c|}{ PRESSURE INTERVALS (PSI) ( \pm 50 psi) } & \multirow{2}{*}{$\begin{array}{c}\text { BURST } \\
\text { PRESSURE } \\
\text { (PSI) }\end{array}$} & \multirow{2}{*}{$\begin{array}{l}\text { MAXIMUM } \\
\text { PLASTIC } \\
\text { DEFORMATION } \\
(\mathrm{mm})\end{array}$} \\
\hline & & 0 & 500 & 1000 & 1500 & 2000 & & \\
\hline T1 & $\begin{array}{c}\text { INDICATOR } \\
\text { READING }(\mathrm{mm})\end{array}$ & & & & & & & \\
\hline T2 & $\begin{array}{c}\text { INDICATOR } \\
\text { READING (mm) }\end{array}$ & & & & & & & \\
\hline T3 & $\begin{array}{c}\text { INDICATOR } \\
\text { READING }(\mathrm{mm})\end{array}$ & & & & & & & \\
\hline T4 & $\begin{array}{c}\text { INDICATOR } \\
\text { READING }(\mathrm{mm})\end{array}$ & & & & & & & \\
\hline T5 & $\begin{array}{c}\text { INDICATOR } \\
\text { READING }(\mathrm{mm})\end{array}$ & & & & & & & \\
\hline T6 & $\begin{array}{c}\text { INDICATOR } \\
\text { READING }(\mathrm{mm})\end{array}$ & & & & & & & \\
\hline T7 & $\begin{array}{c}\text { INDICATOR } \\
\text { READING (mm) }\end{array}$ & & & & & & & \\
\hline T8 & $\begin{array}{c}\text { INDICATOR } \\
\text { READING }(\mathrm{mm})\end{array}$ & & & & & & & \\
\hline T9 & $\begin{array}{c}\text { INDICATOR } \\
\text { READING }(\mathrm{mm})\end{array}$ & & & & & & & \\
\hline T10 & $\begin{array}{l}\text { INDICATOR } \\
\text { READING }(\mathrm{mm})\end{array}$ & & & & & & & \\
\hline
\end{tabular}

Table 3. Irradiation Capsule Burst Test Documentation 

APPENDIX B. FORMS 
Table B-1 Instrument Calibration Log

\begin{tabular}{|l|l|l|l|}
\hline \multicolumn{1}{|c|}{ Instrument } & \multicolumn{1}{|c|}{ Serial Number } & Calibration Number & Calibration Date \\
\hline $\begin{array}{l}\text { DIGITAL } \\
\text { INDICATOR }\end{array}$ & 14130678 & SO 84751 & $2 / 27 / 15$ \\
\hline $\begin{array}{l}\text { PRESSURE } \\
\text { GAGE }(0-10,000 \text { PSi })\end{array}$ & & MTE 31321 & $9 / 10 / 15$ \\
\hline & & & \\
\hline & & & \\
\hline & & & \\
\hline
\end{tabular}

